NOTAS HISTÓRICAS

Rev Chil Salud Pública 2014;

Vol 18 (2): 220-222

\section{PROYECTO DE PUESTA EN VALOR DE LOS HALLAZGOS CULTURALES DEL SECTOR DE LA FUTURA ESTACIÓN HOSPITALES DE LA LÍNEA 3 DEL METRO DE SANTIAGO}

A principios del 2013 y en el contexto de los trabajos de construcción de piques y galerías de la Línea 3 de Metro S.A., para la futura estación Hospitales, se realizaron sondeos y excavaciones arqueológicas con sus profesionales. Estos trabajos abarcaron gran parte de lo que era la Plaza Blest de la Facultad de Medicina de la Universidad de Chile. Los resultados obtenidos por la arqueóloga Verónica Reyes y su equipo dieron cuenta de la existencia de rasgos propios de estructuras arquitectónicas y materialidades asociadas a una edificación, tales como cimientos de muros, recintos, pavimentos, acequia, vidrio, cerámica, restos óseos, vainas de proyectiles y canicas de barro. En informes de avance, los restos del inmueble se describieron señalando que "...poseen una evidente filiación con la denominada 'casa chilena tradicional'...” (Galarce y Reyes 2013).

Por lo anterior, y por el interés de parte de la Universidad de Chile, de la Facultad de Medicina y de sus académicos, en la salvaguarda del patrimonio cultural del país, es que se solicitó a Metro S.A. que en vista de los hallazgos encontrados en dependencias de la universidad, se realizaran los estudios necesarios para la puesta en valor de los restos y que esta se realizara en las instalaciones de la nueva estación.

Para este fin, la Universidad de Chile tomó contacto con el equipo de Ámbito Consultores Ltda. para que se encargara del desarrollo del proyecto de puesta en valor de los hallazgos culturales encontrados en el pique y del estudio de los restos. Con este propósito se formó una mesa técnica por parte de la Universidad, compuesta por historiadores, arqueólogos, arquitectos y conservadores, para la supervisión del proyecto.

El equipo de Ámbito Consultores, compuesto por arquitectos especialistas en patrimonio, arqueólogos, historiadores, geólogos y conservadores chilenos, con la asesoría de expertos mexicanos y griegos, entre otros, comenzaron los trabajos con la premisa de que el sitio correspondiente a los sectores del pique y estación Hospitales, conforman un único contexto arqueológico-histórico.

\section{METODOLOGÍA}

Desde el punto de vista metodológico, se ha trabajado en conjunto con las distintas disciplinas y profesionales, tanto en gabinete como en terreno. En gabinete, se efectuó una revisión documental de los materiales culturales que se encontraron en el pique, además de los materiales descubiertos durante la 
realización de los pozos de sondeo arqueológico en el sector de la futura estación (sector II). Se han revisado antecedentes históricos, entre los que se cuentan planos y mapas, documentos y crónicas; antecedentes arquitectónicos y urbanos, relativos al emplazamiento y ubicación de la edificación, funcionalidad de los recintos y su organización espacial, entre otros aspectos; y antecedentes arqueológicos relacionados con los hallazgos, principalmente en lo relacionado con los materiales encontrados, su función y su adscripción cronológica. En cuanto al trabajo en terreno, se han llevado a cabo evaluaciones diagnósticas en el área de influencia del proyecto, y la búsqueda de similitudes para entender los restos en su contexto urbano. Por otra parte, el trabajo de campo ha permitido conocer en detalle las etapas constructivas de la edificación, sus límites y las técnicas constructivas empleadas.

\section{ANTECEDENTES E HIPÓTESIS}

De los antecedentes recopilados y de las pruebas materiales obtenidas en el sitio, se ha llegado a la hipótesis de que la construcción encontrada bajo la Plaza Blest de la Facultad de Medicina de la Universidad de Chile, correspondería a una edificación que fue utilizada como escuela primaria de mujeres, probablemente entre las décadas de 1860 y 1880 , sin descartar que la edificación date de varias décadas antes.

Esto nos lleva a pensar que los restos materiales encontrados no solo dan cuenta de un pasado con una posible ocupación colonial o republicana, sino que además ellos son evidencia y testigos del patrimonio de la ciudad en lo relativo a la historia de la Educación Primaria Escolar Pública en Chile, en un sector de la ciudad tan importante para su desarrollo como es La Chimba.

En cuanto a los restos encontrados, hoy se está trabajando para determinar su extensión y poder realizar de forma integral su contextualización e interpretación histórica, arqueológica y arquitectónica, para una futura puesta en valor. La indagación (en proceso) ha permitido reconocer un elemento de valor
Imagen de escaneo 3D del pique y su ampliación, realizada por ReStudio. Se observan cimientos y pisos (Ámbito Consultores 2014).

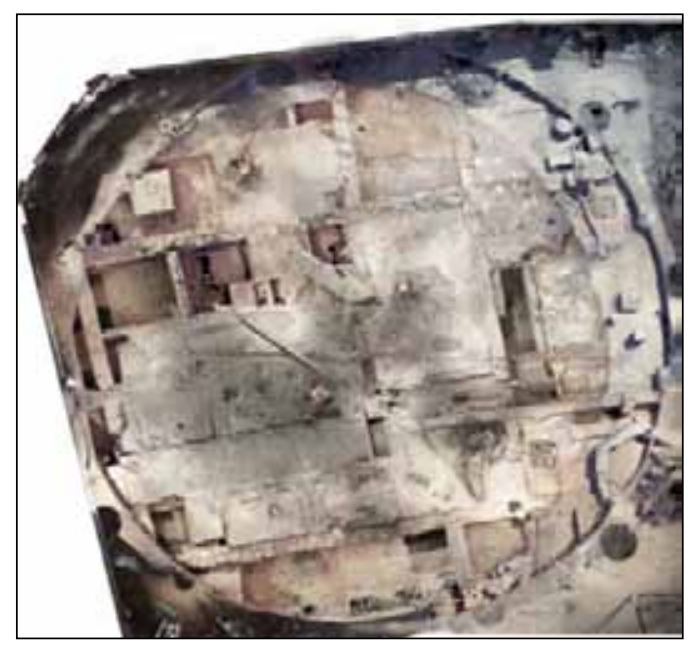

Canicas de barro (Ámbito Consultores 2014)

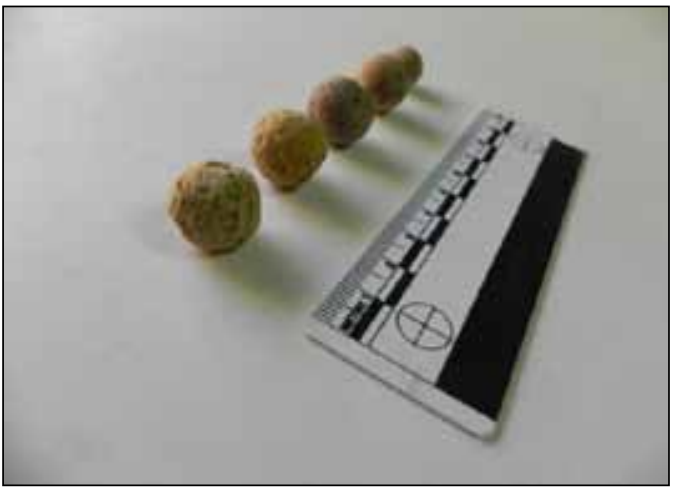

Fragmento pizarra con lado caligráfico y aritmético (Ámbito Consultores 2014)

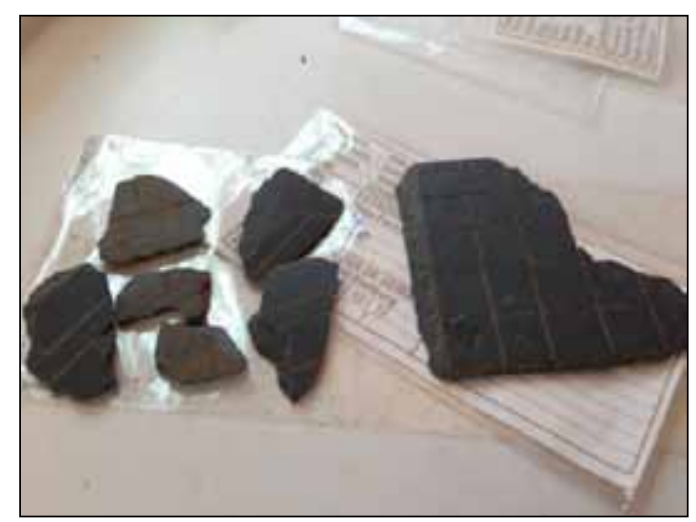


vinculado a lo educacional en un barrio con características particulares, por lo que estaríamos en presencia de una de las primeras escuelas primarias urbanas (¿de mujeres?), bajo la Ley de Instrucción Primaria promulgada en Chile a mediados del siglo XIX, con un factor de excepcionalidad por cuanto no existen a la fecha hallazgos de otras escuelas, además de las ubicadas en la zona.

La escuela, graficada en el plano de Ansart de 1875 en el predio de la "esquina” de Av. Independencia y Zañartu, sería coherente con el mandato de la "Ley Jeneral de Instrucción Primaria” del 24 de noviembre de 1860. Esta señaló en su Artículo 4, que debía haber una escuela elemental de niños y otra de niñas, por cada 2 mil habitantes, y en su Artículo 7, que todos los conventos y conventillos de órdenes regulares y monasterios de monjas debían mantener una escuela, anexa o no, de acuerdo con sus rentas, y el gobierno decidiría si sería elemental o superior. Por su parte, el Censo de 1875 indicaría que la población general de la Subdelegación No 24 "Huechuraba", a la que pertenecía en ese entonces la esquina de Zañartu con Independencia, contaba con 4 mil habitantes, sustentando la necesidad de la existencia de escuelas en la zona, lo que justificaría el apoyo a cualquier empresa que permitiera contar con instrucción primaria en este sector del barrio ultra-Mapocho.

A partir de los antecedentes revisados, se sabe que hacia 1840-1850, la infraestructura de las escuelas era muy disímil; su construcción era a partir de ranchos de paja, ramadas sostenidas por estacas, bodegas, hasta galpones ruinosos. Muchas eran piezas cedidas por la municipalidad, frecuentemente en habitaciones arrendadas en casas particulares, generalmente del mismo preceptor que, por tanto, vivía y educaba en el mismo lugar. Conformadas por un salón pequeño, de unos veinticuatro metros cuadrados, mientras que el de mayor superficie no pasaba los cien metros cuadrados. Algunas escuelas tenían dos salones separados por un tabique. Habitual también era su sobrepoblación y su precaria iluminación y ventilación: muy calurosas en verano y frías en invierno. Los vanos de ventanas no tenían vidrios. Los pisos de barro o de enladrillado ligero favorecían la humedad y el surgimiento de enfermedades en niños y niñas. Tampoco tenían un terreno para el recreo y muy pocas contaban con agua (Ámbito Consultores Ltda. 2014).

\section{POTENCIALIDADES Y FUTURO}

Si bien desde el punto de vista de la historia no se ha podido establecer alguna prueba documental certera, que vincule la edificación con una escuela primaria, la evidencia de fuentes cartográficas y descripciones escritas, junto a la materialidad encontrada, no descarta la hipótesis y, muy por el contrario, nos sigue llevando en dicha dirección, en una labor que aún se encuentra en desarrollo.

Los trabajos que restan son la excavación extensiva del area correspondiente a la Etapa II del proyecto (sector Estación), lo que permitirá tener un visión más completa de la extensión de las edificaciones ya descubiertas y, a partir de ello, aportar al conocimiento de los restos y a la definición de su puesta en valor. Posteriomente, se realizará una etapa de rescate de los restos, los que junto a los retirados en la etapa anterior, se destinarán transitoriamente al Archivo de la Universidad de Chile, para que sean reintegrados cuando la estación se construya.

En este momento el proyecto se encuentra en una fase de elaboración del anteproyecto de puesta en valor, para que sea incorporado al proyecto de arquitectura que Metro S.A. desarrolla para la estación y, al mismo tiempo, se ha considerado relevante la visibilización y difusión de los hallazgos hacia la comunidad, de forma que esta se acerque a este patrimonio urbano, para mantenerlo en la memoria colectiva y promover su apropiación y conservación.

Los restos materiales están a resguardo del Archivo Central Andrés Bello de la Universidad de Chile, donde arqueólogos y conservadores realizan pasantías, prácticas y tesis, con materialidades que han sido poco estudiadas al día de hoy, tales como ladrillos, cueros y piedra pizarra, entre otros.

Mayo 2014 